\title{
A Study on the College English Learning Strategies Based on Intellectual Teaching Platforms*
}

\author{
TAN Xiaoping \\ Leshan Normal University, Sichuan, China
}

\begin{abstract}
Taking Leshan Normal University as an example, the investigation has been conducted in this paper on the use of learning strategies of more than 3,000 non-English majors in the process of English learning. Based on the analysis of the survey results, this paper discusses the necessity of college English learning strategy cultivation under the new situation, focusing on the cultivation approaches to college English learning strategy through intelligent teaching platforms, aiming to cultivate student's awareness of using learning strategies, strengthen their according ability, and improve their English level.
\end{abstract}

Keywords: intelligent teaching platforms, college English learning, strategy instruction

\section{Introduction}

Internet booming and the birth of new media, especially with the utilization of smart mobile devices, have witnessed the rise of intellectual education. Intellectual education is the informatization of education, which is an educational information ecosystem based on Internet of Things (IoT), cloud computing, and wireless communication, and with the features of interconnected, intellectualized, instrumented, and ubiquitous. Its goal is to build up a technology fused learning environment to provide teachers with a platform to conduct new and highly-effective teaching methods, and provide learners with a suitable and customized learning experience. The rise of intellectual education has brought a tremendous impact and challenge to English education. As Professor Liu Runqing (2014) put it, the deep integration of information technology and education would bring forth a systematic change, and exert a profound impact to such aspects as teacher's roles, student's roles, learning material, learning environment, and learning evaluation and tests. Therefore, teachers should update their philosophy of teaching, try new teaching methods, and push education innovation forward. Meanwhile, online and offline combined "Internet + teaching" model will become the new normal, whose features could be concluded as "anybody, anywhere, anytime” (Wei \& Cheng, 2018). Under this circumstance, various intellectual education platforms, like "MOOC”, "M-learning”, "Micro-lecture”, and "Flipped Classroom”, have mushroomed to meet the demand. Facing such abundant teaching resources and choices, how can learners make the best choice and how can they use, adjust, and reconstruct their existing foreign language learning strategies to maximize their effects? And how can teachers help learners to develop their most ideal strategies? Such are new problems that need to be settled in no time and also a great challenge that both teachers and students are meeting.

\footnotetext{
* Acknowledgement: This paper is one of the achievements of the project "A Study on the College English Learning Strategies Based on Intellectual Teaching Platforms" sponsored by the Sichuan Foreign Language Literature Research Center (No. SCWYH19-16).

TAN Xiaoping, Bachelor’s degree, professor, School of Foreign Languages, Leshan Normal University, Sichuan, China.
} 


\section{Literature Review}

Studies on foreign language learning strategies started in around 1970s. Early studies mainly focused on the description and classification of strategies, and on the strategies of successful learners. Chamot (1987) defined the strategy as techniques, methods, or intended actions that a student takes in order to improve his learning effect and to form some easy-to-remember language forms. O’Malley and Chamot (1990) classified the strategies as metacognitive strategies, cognitive strategies, and social affective strategies in accordance of information processing theory. Oxford (1989) defined the strategy as the behaviors or actions that language learners take to make language learning more successful, more purposeful, and more pleasant. Then, Oxford (1990), from the perspective of the relation between language learning strategy and language materials, classified the strategy as direct strategies (memory strategy, cognitive strategy, and compensation strategy) and indirect strategies (metacognitive strategy, affective strategy, and social strategy). Cohen (1998) classified the strategy as language learning strategy and using strategy from the purpose of using it. Mckeachie et al. (1990) classified the strategy, from the portion that learning strategies cover, as cognitive strategies (rehearsal strategy, elaborative strategy, and organizational strategy), metacognitive strategies (planning strategy, monitoring strategy, and adjustment strategy), and resource managing strategies (time managing strategy, learning environment managing strategy, effort managing strategy, and social resources managing strategy). Studies made by O’Malley and Chamot (1990), Mendelsohn (1999), and Vandergrift (1999) showed that an effective use of cognitive strategy, metacognitive strategy, and social affective strategy will equip a student with a feeling that he has controlled the learning process and hence strengthen his confidence.

English learning strategy study in China started in 1980s and attracted a wide attention since mid-1990s. Chinese scholars, like Wen Qiufang (1996; 2003), Cheng Xiaotang and Zheng Min (2002), Wu Benhu (2002), Xiao Jianzhuang (1997), and Yin Fulin (2002), had discussed in macro prospective on the concept and definition of English learning and wrote down in monographs. Zheng Yurong (2010) made a statistics from China's 13 core journals' articles on foreign languages studies between 2000 and 2009 and found the research outputs were increasing year by year, and the study scope covers a wide range; however, the discussions on studies on the relation between the use of strategies and language learning achievements were not deep enough and most researches were focused on a single strategy. Only a few of them made researches with an integration of different strategies. Looking through recent years' researches, we can see the research on mobile learning strategies based on Internet technologies and intellectual teaching platforms are too limited. In the incoming big data era, it is timely and necessary to explore college English learning strategies on intellectual teaching platforms.

\section{Investigation Into the Current Situation of Student's Learning Strategies}

To have a clear idea of the current situation of student's use of learning strategies and to help them take advantage of good and valuable English learning strategies, the author investigated the use of learning strategies of freshmen and sophomores who are non-English majors in Leshan Normal University on SO JUMP, a professional online questionnaire platform, and collected 3,318 effective responses. Based on the survey results, the average values of memory strategy, cognitive strategy, remediation strategy, metacognitive strategy, emotional strategy, and social strategy remain low, among which the remediation strategy ranks first, emotional strategy, metacognitive strategy, memory strategy, and social strategy are in the middle level, while cognitive 
strategy stays weak. The average value of remedial strategies is relatively high, which means that students can consolidate their English learning by different means. At the same time, the standard deviation of remedial strategies is relatively low, which implies that most students have got this awareness. Emotional strategies and metacognitive strategies rank behind remedial strategies, and their standard deviation is relatively high and close to each other, which shows that most students have a positive attitude towards English learning and can consciously review their cognitive strategies. But a small number of students are expected to improve in these two aspects. Memory strategy is the basic skill of language learning, whose lower ranking mainly reflected student's insufficient grouping, induction and memory of language structure and content. And the standard deviation of memory strategy is relatively low, which indicates that there is not much difference in student's individual use of this basic strategy. Social strategies rank behind memory strategies, manifesting that most students are not good at communication, and the high standard deviation has made it clear that each student's situation varies from person to person. Cognitive strategies are listed last with a low average, which demonstrates that most students have not yet mastered the cognitive rules and skills of English learning.

Generally speaking, most students do not attach much importance to the use of learning strategies. The results of the following two questions have illustrated this point.

\section{The Necessity of Improving College English Learning Strategies Under the New Situation}

As science and technology develop dramatically, intelligent education is emerging with various intelligent education platforms coming out in an unending flow, educational resources overwhelming. Under the new situation, the goal of education is no longer limited to knowledge instruction. Instead, it is to teach them the methods and means to acquire knowledge, making sure they can be an independent learner with critical thinking (Zhao, 2019). As Rousseau, a French thinker and educator, said, it is more important to develop self-directed learning method than to acquire knowledge. The learning method here refers to the learning strategy. A large number of research results at home and abroad show that there is a correlation between the use of learning strategies and language learning, which greatly affects the learning effect of learners. Wen Qiufang (1996) believed that the differences of English learning strategies have a decisive impact on the achievement with all other things being equal. Naturally, teachers are supposed to help students improve effective learning strategies as only when students master learning strategies can they be good at learning and enjoy learning, as well as improve their learning performance at a large scale. Meanwhile, only when they form their own learning strategies, can they be good at thinking and practice hard, keep forging ahead, also generate innovation desire and ability. Therefore, learning strategies play a significant role in foreign language learning, and it is necessary to cultivate student's English learning strategies.

\section{Approaches to Improving Student's Learning Strategies}

The application of learning strategies is directly related to student's English learning. So, we can try the following approaches to the development of strategies.

\section{Strengthening Student's Awareness of Using Learning Strategies}

Judging from the results of the questionnaire survey, a great number of students have little knowledge of learning strategies, and there is almost a complete lack of awareness of it. Therefore, it is necessary to introduce to student's classification, concepts, value, and possible effects of learning strategies. When necessary, teachers 
can give specific demonstrations to allow students to see the different learning effects brought by the use of strategies, so as to cultivate their awareness of using strategies.

\section{Guiding Students to Practice Using Learning Strategies}

No practice will not achieve good results. Therefore, teachers need to design some tasks in accordance with the content of the textbook, so that students can actually practice the strategic knowledge they learn in specific tasks, and they can have a clear understanding of strategies from sensibility to rationality. And then, they are willing to use strategies. For example, after the teacher introduces metacognitive strategies, he can assign students oral practice tasks on the FIF oral training system. The students then can make their own learning plans based on the tasks, and follow the plans to perform oral practice and complete the tasks. Teachers use the feedback information on the FIF oral training system to monitor the study progress of the students in real time. At the same time, students should formulate regular self-monitoring and review plans for the progress of their exercises. The FIF oral training system supports the function of repeated practice to refresh the score, so the student can repeatedly practice the part with a lower score, and refresh the score given by the system before the end of the task. Combined with the scores, students can assess the practice process and practice results by themselves. Students first set practice goals and plans for themselves, then manage and monitor their own learning process, at last evaluate and test their learning effects at the end of the training. In this loop process, the students can master metacognitive strategies gradually, and use them consciously.

Teachers can also use the FIF oral training system to train students on resource management strategies. Resource management strategies mainly include strategies of time management, learning environment management, effort management, and seeking support. Effective use of these strategies can help students adapt to the environment and adjust the environment to suit their needs. When arranging FIF oral practice tasks, teachers should give students as much time as possible to allow them to arrange their exercises properly. Meanwhile, students can choose a certain time to complete the oral English practice when they are in a happier mood, having clearer ideas, and easier to concentrate. A good oral practice environment should be created for students, so that they can complete their practice more efficiently. The FIF platform provides a wealth of learning resources, and students should be taught to choose learning content suitable for them. If in doubt, it is best to consult a teacher or classmate. Mutual cooperation and discussion among classmates help to inspire each other and achieve a comprehensive understanding. Through consultation, cooperation, and other methods it can increase student's opportunities to use English. Through active interaction in teaching and learning, students can gradually develop their own learning strategies (Pan \& Hou, 2018).

\section{Organizing Students to Discuss Learning Strategies}

The strategy itself cannot be judged as good or bad. The key point is that the learner should make the appropriate choice of strategy for the right task at the right time. No matter what strategy is chosen, as long as it can solve the current problem efficiently, it is effective for the learner (Qi, 2014). Since many factors, such the learner, the time, the learning conditions, will affect the choice of strategies, we cannot make uniform requirements for how students use learning strategies for a certain task in a certain time. As Ellis and Sinclair (1989) pointed out, "Strategy training provides learners with an additional option in choosing what to learn, how to learn, why to learn, when to learn, and where to learn” (p. 44). For instance, after being trained on word memorizing strategies, students can share their chosen strategies for each word in a unit from the textbook, one 
by one, for other students to learn from. Then, they can try to use various words memorizing strategies and choose the one that works best for themselves.

\section{Conclusion}

Learning strategy is an important research project in the field of education and psychological science. Instructing students to master effective learning strategies is not only conducive to improving the learning effect and reducing the burden of learning, but also to improving the quality of education substantially. It is for sure that the study of learning strategies requires learners to analyze their own learning process, plan, and evaluate their own learning behaviors according to their analysis results, so as to decide on the specific learning strategies they need. But learning strategy awareness is not innate, but to be trained. Teachers can take advantage of intelligent teaching platforms to enhance student's awareness of using strategies through classroom and extra-curricular training, explicit and implicit training, group and individual training, so as to provide students with practice opportunities for learning strategies, and help them use these strategies under the new learning conditions, so that they can develop the habit of selecting, evaluating, and reflecting learning strategies to improve their ability of autonomous learning with sustainable development. As a result, students can achieve twice the result with half the effort in foreign language learning.

\section{References}

Chamot, A. (1987). The learning strategies of ESL students. In A. Wenden and J. Rubin (Eds.), Learner strategy in language learning (pp. 71-83). Englewood Cliffs, NJ: Prentice Hall, Inc.

Cheng, X. T., \& Zheng, M. (2002). English learning strategies_From theory to practice. Beijing: the Foreign Language Teaching and Research Press.

Cohen, A. D. (1998). Strategies in learning and using a second language. New York: Longman.

Ellis, G., and Sinclair, B. (1989). Learning to learn English. Cambridge: Cambridge University Press.

Huang, Y. L. (2019). Research on college English autonomous learning ability training strategy under the $3+1+\mathrm{X}$ teaching mode. Comparative Study of Cultural Innovation, (6), 146-147.

Liu, R. Q. (2014). Foreign language education and research in the era of big data. Modern Foreign Language Research, (11), $14-19$.

McKeachie et al. (1990). Teaching and learning in the college classroom: A review of the literature (2nd ed.). Ann Arbor: University of Michigan.

Mendelsohn, D. J. (1999). A guide for the teaching of second language listening. San Diego, CA: Dominie Press.

O’Malley, J. M., \& Chamot, A. U. (1990). Learning strategies in second language acquisition. Cambridge: Cambridge University Press.

Oxford, R. (1989). The use of language learning strategies: A synthesis of studies with implications for strategy training. System, $12(2), 235-247$.

Oxford, R. (1990). Anxiety and the language learners: New insights. In J. Arnold (Ed.), Affect in language learning (p. 7). Cambridge: Cambridge University Press.

Pan, L. P., \& Hou, S. (2018). Research on learning ways of English wisdom classroom in online open course platform environment. Journal of Hebei Energy Institute of Vocation and Technology, (3), 17-20.

Qi, C. (2014). Empirical study on learning strategies instruction to College English poor learners (Doctoral dissertation, Northeast Normal University).

Vandergrift, L. (1999). Facilitating second language listening comprehension: Acquiring successful strategies. ELT Journal, 53(3), 168-176.

Wei, F., \& Cheng, N. (2018). Research on college English autonomous learning strategy based on the Internet. China Journal of Multimedia Network Teaching, (8).

Wen, Q. F. (1996). On English learning strategies. Shanghai: Shanghai Foreign Language Education Press.

Wen, Q. F. (2003). A successful way to English study. Shanghai: Shanghai Foreign Language Education Press 
Wu, B. H. (2002).The English learning strategies. Anhui: Anhui Education Press.

Xiao, J. Z. (1997). The English learning strategies. Beijing: Modern Press.

Yin, F. L. (2002). High marks research on English for postgraduate admission examination. Hefei: Press of University of Science and Technology of China.

Zhao, S. X. (2019). The transformation and strategies of college English teaching and learning in the era of artificial and intelligence. Journal of Anshun University, (12), 73-77.

Zheng, Y. R. ( 2010). A survey of English learning strategies in China. Foreign Language World, (3), 82-88. 